\title{
Short-Chain Fatty Acids Inhibit Growth Hormone and Prolactin Gene Transcription via cAMP/PKA/CREB Signaling Pathway in Dairy Cow Anterior Pituitary Cells
}

Jian-Fa Wang ${ }^{1,2, \dagger}$, Shou-Peng Fu ${ }^{1, \dagger}$, Su-Nan Li ${ }^{1, \dagger}$, Zhong-Ming Hu ${ }^{3, \dagger}$, Wen-Jing Xue ${ }^{1}$, Zhi-Qiang Li ${ }^{1}$, Bing-Xu Huang ${ }^{1}$, Qing-Kang Lv ${ }^{1}$, Ju-Xiong Liu ${ }^{1}{ }^{*}$ and Wei Wang ${ }^{1}{ }^{*}$

1 College of Veterinary Medicine, Jilin University, Changchun 130062, China;

E-Mails: wjflw@sina.com (J.-F.W.); shoupengfu@163.com (S.-P.F.);

1snlhh2006@163.com (S.-N.L.); zhulingxue_1991@163.com (W.-J.X.);

w120658200@163.com (Z.-Q.L.); huangbingxu123@gmail.com (B.-X.H.);

lvqingkang@hotmail.com (Q.-K.L.)

2 College of Animal Science and Veterinary Medicine, Heilongjiang Bayi Agricultural University, Daqing 163319, China

3 Laboratory of the Animal Center, Academy of Military Medical Sciences, Beijing 100850, China; E-Mail: huzhongming2005@sina.com

$\dagger$ These authors contributed equally to this work.

* Authors to whom correspondence should be addressed; E-Mails: juxiongliu@sina.com (J.-X.L.); wang_wei99@jlu.edu.cn (W.W.); Tel./Fax: +86-431-8783-6163 (J.-X.L. \& W.W.).

Received: 6 August 2013; in revised form: 26 September 2013 / Accepted: 30 September 2013 / Published: 30 October 2013

Abstract: Short-chain fatty acids (SCFAs) play a key role in altering carbohydrate and lipid metabolism, influence endocrine pancreas activity, and as a precursor of ruminant milk fat. However, the effect and detailed mechanisms by which SCFAs mediate bovine growth hormone $(G H)$ and prolactin $(P R L)$ gene transcription remain unclear. In this study, we detected the effects of SCFAs (acetate, propionate, and butyrate) on the activity of the cAMP/PKA/CREB signaling pathway, GH, PRL, and Pit-1 gene transcription in dairy cow anterior pituitary cells (DCAPCs). The results showed that SCFAs decreased intracellular cAMP levels and a subsequent reduction in PKA activity. Inhibition of PKA activity decreased CREB phosphorylation, thereby inhibiting $G H$ and $P R L$ gene transcription. Furthermore, PTX blocked SCFAs- inhibited cAMP/PKA/CREB signaling pathway. These data showed that the inhibition of $G H$ and $P R L$ gene transcription induced by SCFAs is 
mediated by Gi activation and that propionate is more potent than acetate and butyrate in inhibiting $G H$ and $P R L$ gene transcription. In conclusion, this study identifies a biochemical mechanism for the regulation of SCFAs on bovine $G H$ and PRL gene transcription in DCAPCs, which may serve as one of the factors that regulate pituitary function in accordance with dietary intake.

Keywords: short-chain fatty acids; dairy cow; growth hormone; prolactin; G protein

\section{Introduction}

The pituitary plays a critical role in animals and regulates a broad range of physiological processes involved in growth, metabolism, reproduction, lactation, and stress [1]. Growth hormone (GH) is a polypeptide hormone synthesized and secreted by the anterior pituitary gland. It plays a key role in regulating ruminant mammary gland development and lactation [2]. In lactating cows, bovine GH induces proliferation of mammary parenchyma and growth of epithelial cells, and increase the cell renewal in the mammary gland [3]. GH increases milk protein gene expression in bovine mammary explants and mammary epithelial cells [4,5]. Prolactin (PRL) is a polypeptide hormone that is synthesized in and secreted from lactotrophs of the anterior pituitary gland [6]. PRL also play a key role in regulating mammary gland development and lactation [7]. Because of the irreplaceable regulatory role in growth, metabolism, and lactation, researches on endocrinology always focus on the factors and mechanisms affecting GH and PRL synthesis and release.

Short-chain fatty acids (SCFAs), including acetate, propionate, and butyrate, are formed during bacterial fermentation of carbohydrates in the gut or rumen of various animal species [8]. Dietary nutrients play an important role in regulating rumen fermentation and SCFAs synthesis. The rumen ratio of acetate to propionate to butyrate is approximately 70:20:10 in lactating dairy cows, and the mean concentrations of plasma acetate, propionate, and butyrate are $0.4,0.1$, and $0.5 \mathrm{mmol} / \mathrm{L}$ in dairy cows [9]. SCFAs have multiple in vivo and in vitro effects including mediate inflammation, alter carbohydrate and lipid metabolism, regulate cell proliferation and differentiation, influence endocrine pancreas activity, provide an additional source of energy for the body, and as a precursor of ruminant milk fat [10-13]. In addition to these, SCFAs are known to have in vivo and in vitro actions on pituitary hormone secretion function. Addition of sodium-butyrate to milk formula increased the secretion of GH and insulin level in pre-weaning calves [14]. The sodium salts of butyric, valerate, hexanoic, caprylic, nonanoic, and dodecanoic acids increased GH and prolactin (PRL) secretion in GH3 cell [15]. By contrast, the reported effects of SCFAs on GH secretion are still controversial. Ishiwata et al. found that addition of propionate or butyrate to the anterior pituitary cells of the goat cultured in vitro inhibited GHRH-induced GH release and GH production [16]. Therefore, the effect and detailed mechanisms by which SCFAs mediate bovine pituitary function need to be elucidated.

In 2003, two orphan G protein coupled receptors (GPCRs), GPR41 and GPR43 have been identified as cell-surface receptors for SCFAs [17]. Both GPR41 and GPR43 are coupled with $\mathrm{G}_{\mathrm{q}}$ and $\mathrm{G}_{\mathrm{i} / \mathrm{o}}$, and their activation can induce an increase in intracellular calcium concentration and suppress cellular cyclic adenosine 3',5'-monophosphate (cAMP) accumulation [18]. Wang et al. has proved that GPR41 and 
GPR43 mRNA are expressed in bovine pituitary gland [19]. Pituitary-specific positive transcription factor 1 (Pit-1) was first discovered as the transcription factor that is necessary for the expression of $G H$ and $P R L$ [20]. The proximal promoters of the rat $G H$ gene include binding sites for Pit-1, specificity protein 1 (Sp1), cAMP-response element binding protein (CREB), and thyroid hormone response element (TRE) [21,22]. The promoters of the rat PRL gene include binding sites for Pit-1, estrogen response element (ERE), and Ets binding sites (EBS) [6]. The Pit-1 promoter contains a binding site for Pit-1 and two CREB binding sites [23]. Thus, the change of phosphorylation levels of CREB could change $G H$ and $P R L$ gene transcription level directly or indirectly. We hypothesize that SCFAs may mediate bovine $G H$ and $P R L$ gene transcription via the $\mathrm{G}$ protein signaling pathway. Therefore, the objective of this study was to determine the effects of SCFAs on the activity of G protein signaling pathway, GH, PRL, and Pit-1 gene transcription in dairy cow anterior pituitary cells (DCAPCs). The results of this study could provide important information for understanding the role of the $G$ protein signaling pathway in SCFAs mediate bovine pituitary function.

\section{Results}

\subsection{Effect of SCFAs on mRNA Levels of GH, PRL and Pit-1 in DCAPCs}

The mRNA levels of $G H$ and $P R L$ showed a decreasing trend in the SCFAs-treated groups. The mRNA levels of $G H$ were significantly lower in the 0.1 and $0.5 \mathrm{mmol} / \mathrm{L}$ acetate and $0.5,1.0,2.5$ and $5.0 \mathrm{mmol} / \mathrm{L}$ butyrate groups than in the control groups (Figure $1 \mathrm{~A} ; p<0.05$ ), and the mRNA levels of $G H$ were markedly lower in the 1.0, 2.5 and $5.0 \mathrm{mmol} / \mathrm{L}$ acetate and $0.1,0.5,1.0,2.5$ and $5.0 \mathrm{mmol} / \mathrm{L}$ propionate groups than in the control groups (Figure 1A; $p<0.01$ ), respectively. The mRNA levels of $P R L$ were significantly lower in the $1.0,2.5$ and $5.0 \mathrm{mmol} / \mathrm{L}$ acetate, 0.1 and $5.0 \mathrm{mmol} / \mathrm{L}$ propionate and $0.1,0.5,1.0$ and $5.0 \mathrm{mmol} / \mathrm{L}$ butyrate groups than in the control groups (Figure $1 \mathrm{~B} ; p<0.05$ ), and the mRNA levels of $P R L$ were markedly lower in the $0.5 \mathrm{mmol} / \mathrm{L}$ acetate, $0.5,1.0,2.5 \mathrm{mmol} / \mathrm{L}$ propionate and 1.0 and $2.5 \mathrm{mmol} / \mathrm{L}$ butyrate groups than in the control groups (Figure $1 \mathrm{~B} ; p<0.01$ ), respectively. The transcription of the Pit-1 gene had no obvious change treated by either acetate, propionate or butyrate at $0.1,0.5,1.0,2.5$ and $5.0 \mathrm{mmol} / \mathrm{L}$ (Figure $1 \mathrm{C} ; p>0.05$ ), respectively. The transcription of the $G H$ and $P R L$ gene were significantly higher in the PTX + acetate group than in the $1.0 \mathrm{mmol} / \mathrm{L}$ acetate treatment group (Figure 1D; $p<0.05$ ). The mRNA levels of $G H$ and $P R L$ were markedly higher in the $\mathrm{PTX}+$ propionate group than in the propionate treatment group (Figure 1E; $p<0.01$ ). The mRNA levels of $G H$ and $P R L$ were significantly higher in the PTX + butyrate group than in the butyrate treatment group (Figure 1E; $p<0.01$ ). Taken together, these results strongly suggest that SCFAs significantly down-regulate the expression of $G H$ and $P R L$ gene in DCAPCs, and the mRNA levels of $G H$ and $P R L$ were significantly higher by prior PTX incubation. 
Figure 1. The effect of short-chain fatty acids (SCFAs) on the mRNA levels of GH, PRL and Pit-1 in dairy cow anterior pituitary cells (DCAPCs). DCAPCs were treated with $0,0.1,0.5$, 1.0, 2.5 and $5.0 \mathrm{mmol} / \mathrm{L}$ acetate $(\mathbf{A})$; propionate $(\mathbf{B})$; and butyrate $(\mathbf{C})$ for $24 \mathrm{~h}$, respectively. The cells were also treated with or without prior PTX incubation $(100 \mathrm{ng} / \mathrm{L})$ for $2 \mathrm{~h}$, and then stimulated with $1.0 \mathrm{mmol} / \mathrm{L}$ acetate $(\mathbf{D})$; propionate $(\mathbf{E})$; or butyrate $(\mathbf{F})$ for $24 \mathrm{~h}$, respectively. Each treatment replicated 12 times. $* p<0.05,{ }^{*} p<0.01 v$ s. the control group.
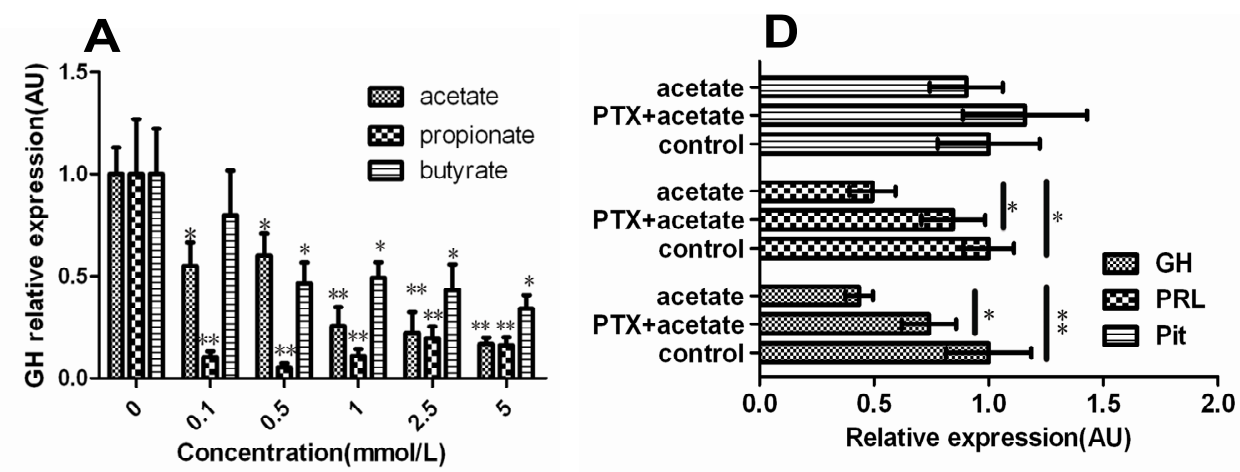

B
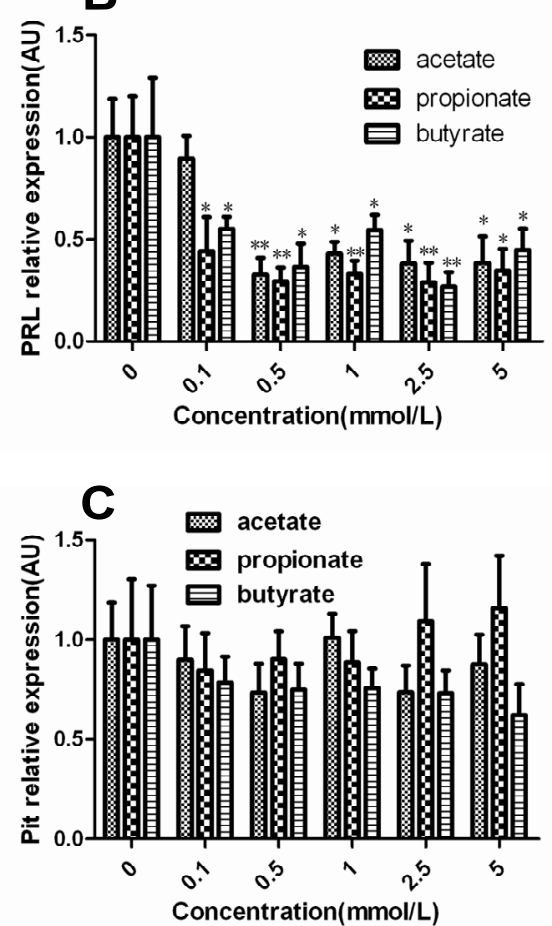
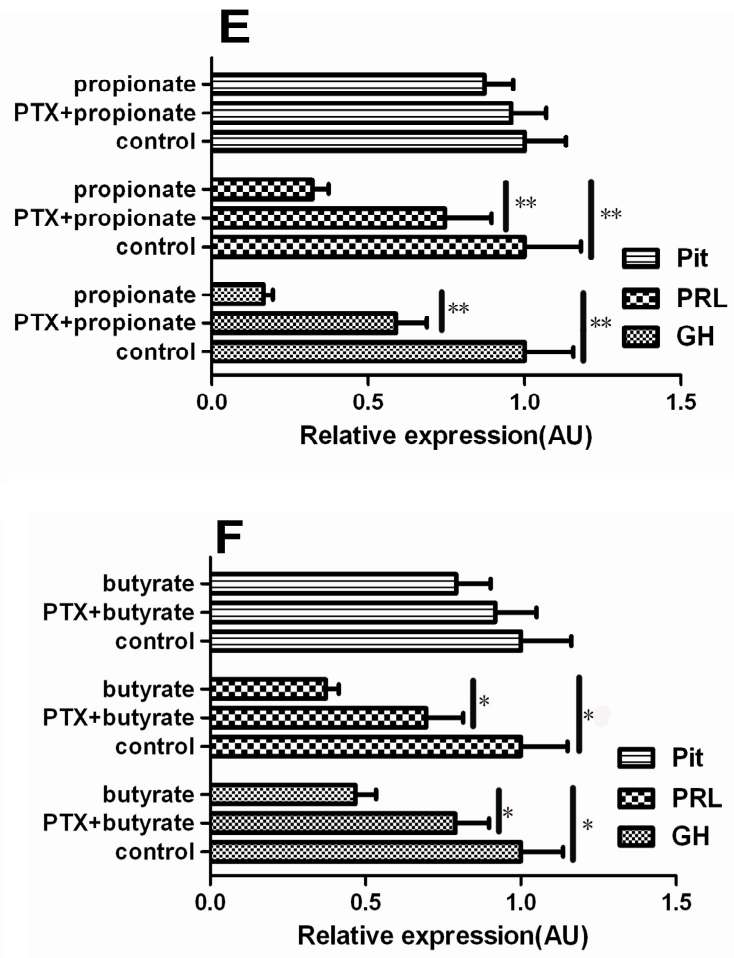

\subsection{Effect of SCFAs on Intracellular cAMP Concentration}

The cAMP levels were lower in the SCFAs-treated groups than in the control group, and both were the lowest at the $3 \mathrm{~h}$ of the SCFAs-treated groups (Figure 2A). The cAMP levels were significantly higher in the PTX + acetate or butyrate group than in the non PTX treatment group (Figure $2 \mathrm{~B} ; p<0.05$ ), respectively. The cAMP level was significantly higher in the PTX + propionate group than in the non PTX treatment group (Figure 2B; $p<0.01$ ). Overall, these results indicate that SCFAs significantly decrease the intracellular cAMP concentration, and the intracellular cAMP levels were significantly decreased by prior PTX incubation. 
Figure 2. The effect of SCFAs on the intracellular cAMP levels in DCAPCs. DCAPCs were treated with $1.0 \mathrm{mmol} / \mathrm{L}$ acetate, propionate, and butyrate for $0,0.5,1.0,2.0$, and $3.0 \mathrm{~h}$, respectively (A); The cells were also treated with or without prior PTX incubation $(100 \mathrm{ng} / \mathrm{L})$ for $2 \mathrm{~h}$, and then stimulated with $1.0 \mathrm{mmol} / \mathrm{L}$ acetate, propionate, or butyrate for $3 \mathrm{~h}$, respectively $(\mathbf{B})$. Each treatment replicated 12 times. ${ }^{*} p<0.05, * * p<0.01$ vs. the control group.
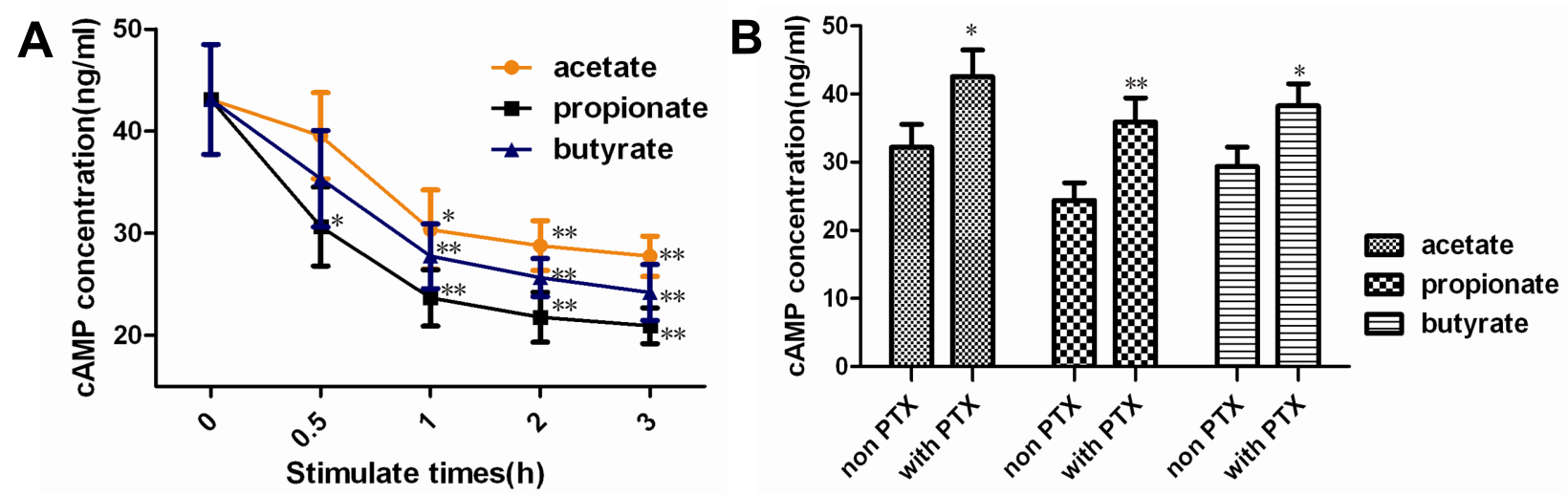

\subsection{Effect of SCFAs on PKA Activity}

The PKA activity was lower in the SCFAs-treated groups than in the control group, and the inhibiting effect of SCFAs was blocked by PTX (Figure 3). The PKA activity was significantly lower in the acetate and butyrate group than in the control group $(p<0.05)$, respectively. The PKA activity was markedly lower in the propionate group than in the control group $(p<0.01)$. The PKA activity was significantly increased in the PTX + propionate group than non PTX group $(p<0.05)$. The PKA activity had no obvious change in the PTX + acetate or butyrate group than non PTX treatment group $(p>0.05)$, respectively.

Figure 3. The effect of SCFAs on the PKA activity in DCAPCs. The cells were treated with or without prior PTX incubation $(100 \mathrm{ng} / \mathrm{L})$ for $2 \mathrm{~h}$, and then stimulated with $1.0 \mathrm{mmol} / \mathrm{L}$ acetate, propionate, or butyrate for $3 \mathrm{~h}$, respectively. Each treatment replicated 12 times. $* p<0.05, * * p<0.01$ vs. the control group; \# $p<0.05$ vs. the non PTX group.

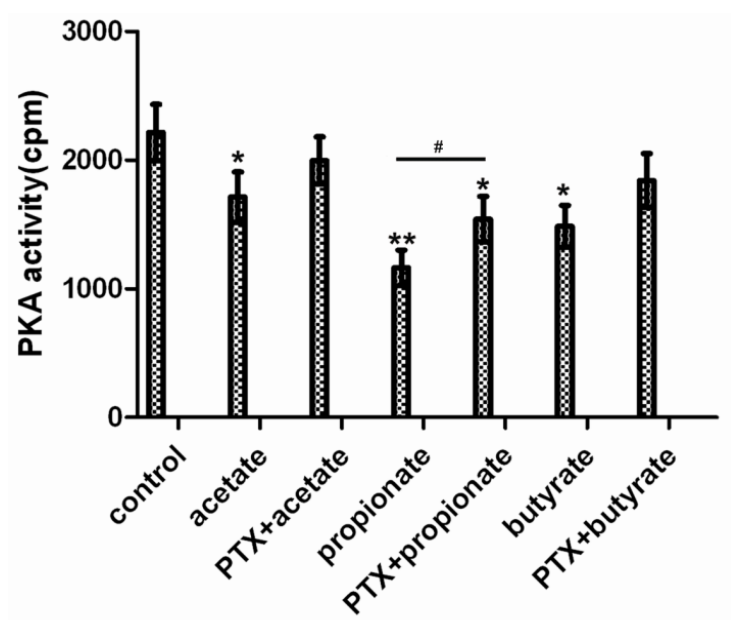




\subsection{Effect of SCFAs on CREB Phosphorylation}

The phosphorylation levels of CREB (Figure 4) were markedly lower in the acetate-, propionate- and butyrate-treated groups than in the control group respectively $(p<0.01)$, and the phosphorylation levels of CREB were markedly higher by prior PTX treatment $(p<0.01)$.

Figure 4. The effect of SCFAs on the CREB phosphorylation in DCAPCs. The cells were treated with or without prior PTX incubation (100 ng/L) for $2 \mathrm{~h}$, and then stimulated with $1.0 \mathrm{mmol} / \mathrm{L}$ acetate, propionate, or butyrate for $6 \mathrm{~h}$, respectively. Each treatment replicated 12 times. $* p<0.05, * * p<0.01$ vs. the control group; \#\# $p<0.01$ vs. the non PTX group.

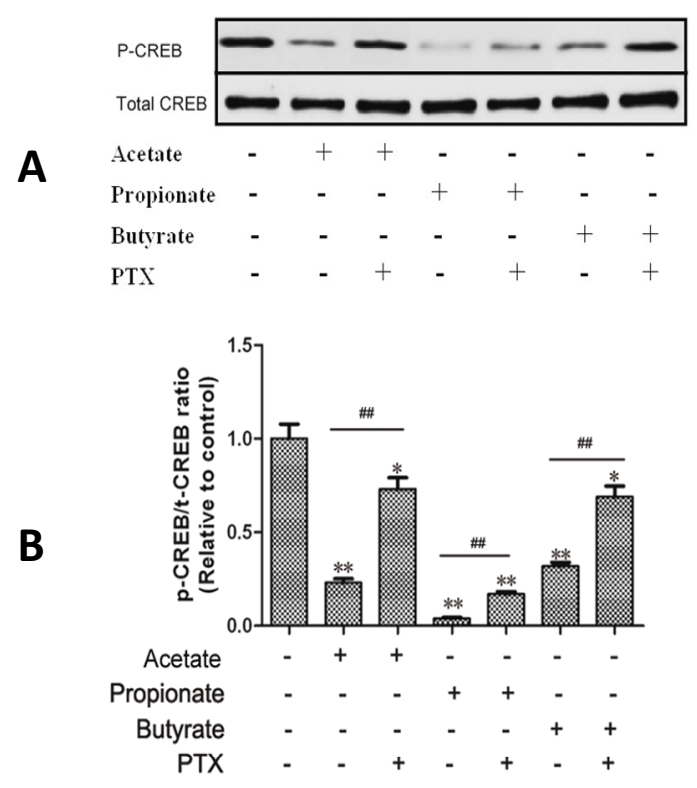

\section{Discussion}

SCFAs, primarily acetate, propionate and butyrate, are organic acids produced within the intestinal lumen or rumen of ruminant by bacterial fermentation of mainly undigested dietary carbohydrates [24]. There has been increasing evidence that the majority of SCFAs play an essential role in maintaining the health of colonic mucosa [25-28]. Due to the important role of SCFAs, researchers are interested in finding the methods to increase intestinal SCFAs concentrations [29,30]. In contrast to the wide range of positive effects of SCFAs on the health, few studies have reported the adverse effects of SCFAs. SCFAs are known to have in vivo and in vitro actions on pituitary secretion function [14-16]. However, the effect and detailed mechanisms by which SCFAs mediate bovine $G H$ and $P R L$ gene transcription remain unclear. More emphasis should be put on $G H$ and $P R L$ gene transcription regulation to elucidate the role of the $\mathrm{G}$ protein signaling pathway in SCFAs mediate bovine pituitary function.

GPCRs are cell surface receptors which serve in the transduction of extracellular stimuli into intracellular signals. They mediate extracellular stimuli into intracellular signals and are indispensable among membrane proteins because they constitute the largest and most diverse groups of receptor proteins. Thus, GPCRs represent one of the most important families of drug targets. The regulatory subunit of $G$ proteins has four classes: $G_{\alpha \mathrm{s}}, G_{\alpha i}, G_{\alpha q}$, and $G_{\alpha 12}$ with respect to sequence homology and functional similarities of their $\alpha$ subunits [31]. The activation of $G_{\alpha i}$ results in an inhibition of adenylyl 
cyclase, hence, decrease in cAMP production [32]. In this study, the cAMP levels were significantly lower in the SCFAs-treated groups than control group. ADP-ribosylation of the $\mathrm{G}_{\alpha i}$-proteins prevents the coupling to their cognate GPCRs and consequently disrupts the signal transduction cascade. Here, we demonstrated that PTX could inhibit SCFAs-induced decrease in cAMP level. This indicates that SCFAs exert their actions through coupled to $\mathrm{G}_{\alpha \mathrm{i}}$ subunit. The biological effects of PTX that result from ADP-ribosylation of the $\mathrm{G}_{\alpha \mathrm{i}}$-proteins are diverse, some of which can be attributed to the pretreatment timing and load dosing. Almost all cell types $\mathrm{G}_{\alpha i}$-protein were nearly completely ADP-ribosylated after a $2 \mathrm{~h}$ incubation with PTX (200 ng/mL) [33]. In most cells, PTX itself only induces an incremental increase in cAMP when the load dosing reach more than $1 \mu \mathrm{g} / \mathrm{mL}$ [33]. Therefore, PTX $(100 \mathrm{ng} / \mathrm{L})$ could not restore the effect of SCFA to the control level in DCAPCs, some of which may be attributed to the load dosing of PTX.

Decrease in cAMP levels results in a subsequent reduction in PKA activity. Then, PKA catalyzes the phosphorylation of serine residues on CREB to activate pit-1 and thus initiate a response within the cell [34]. Our data showed that the PKA activity was lower in the SCFAs-treated groups than in the control group, and the inhibiting effect of SCFAs was blocked by PTX. Moreover, the phosphorylation levels of CREB were lower in the SCFAs-treated groups than in the control group, and this effect was also decreased by prior PTX incubation. Overall, these results indicate that SCFAs could inhibit the activity of cAMP/PKA/CREB signaling pathway in DCAPCs.

In the nucleus, phosphorylated CREB could change $G H$ gene transcription level directly or activate Pit-1 to trigger the transcription of the $G H$ and $P R L$ gene indirectly [34]. In this study, SCFAs significantly down-regulate the expression of $G H$ and $P R L$ gene in DCAPCs, and the mRNA levels of $G H$ and $P R L$ were significantly higher by prior PTX incubation. Based on these observations, we conclude that SCFAs inhibit $G H$ and $P R L$ gene transcription via cAMP/PKA/CREB signaling pathway.

However, the expression of Pit-1 gene was not significantly changed, suggesting that the change of Pit-1 activity may play an important role in the regulation of $G H$ and $P R L$ transcription by SCFA. Three serine-threonine phosphorylation sites have been identified in Pit-1:serine 115 (S115), threonine 219 (T219), and threonine 220 (T220). The S115 and T220 sites are phosphorylated both in cells treated with cAMP or phorbol esters or by directly phosphorylating purified Pit-1 proteins with PKA and PKC [35-37]. Phosphorylation of Pit-1 at both T220 and S115 is elevated in mitotic cells and binding of Pit-1 to the PRL-1p $\mathrm{GHF}_{-1 \mathrm{p}}$, and $\mathrm{GH}_{-1 \mathrm{p}}$ sites was reduced [37]. Thus, we hypothesize that phosphorylated CREB may not mediate bovine $P R L$ gene transcription via increase the phosphorylation levels of Pit-1. The CREB binding protein (CBP) acts as a cofactor for Pit-1-dependent activation of the hGH promoter by the GHRH signaling pathway and PKA [38]. CBP acts by binding to phosphorylated CREB (PKA-dependent) and activating gene expression [39]. For these reasons, phosphorylated CREB may increase the phosphorylated CBP or CBP complex interacts with Pit-1 resultant activation of transcription of the bovine $P R L$ gene. Thus, further studies are needed to understand the exact mechanisms mediating bovine $P R L$ gene by CREB.

SCFAs are the major energy source for dairy cows, which promote rumen development in calves and rumen epithelial papilla growth in lambs [40]. Zhao and Sun found that the concentration of GH in plasma was increased significantly with increasing level of ruminal infusion of mixed SCFAs [41]. Kato et al. found that addition of sodium-butyrate to milk formula increased the secretion of GH and insulin level in pre-weaning calves [14]. However, Matsunaga et al. found that ruminal or mesenteric 
venous infusion of SCFAs significantly suppressed GH secretion in a dose-dependent manner [42-44]. Factors affecting GH or PRL synthesis and secretion in the dairy cow include hypothalamic factors, peripheral hormones, cytokines, and dietary nutrients [6,45]. Thus, there was a very large difference results among in vivo experiments according to the difference physiological state of the animal. Furthermore, the network integrating hormone, neurotransmitters, cytokines, and nutrient signaling in control of GH and PRL synthesis and secretion is complex and make interpretation difficult. It seems, therefore, that existing in vivo approaches are not effective for the investigation the effect and exact mechanisms of SCFAs on the GH and PRL synthesis and secretion in the dairy cows. Cell culture is one of the most convenient tools for understanding the mechanisms of pituitary hormone synthesis and secretion, which provides a powerful tool to uncover new information. Based on these reasons, we established a dairy cow GH and PRL secreting anterior pituitary cell model, which can be used successfully for the study of the mechanisms of hypothalamic factors, peripheral hormones, cytokines, or dietary nutrients regulating GH or PRL synthesis and release [46]. Mean acetate, propionate, and butyrate level in cerebrospinal fluid (CSF) of cattle are lower than in plasma $[47,48]$. In this study, a wide range concentration of SCFAs, which include the physiology concentration of SCFAs in CSF and plasma, was chosen. This study identifies a biochemical mechanism for the regulation of SCFAs on bovine GH and PRL gene transcription in DCAPCs, which may serve as one of the factors that regulate pituitary function in accordance with dietary intake.

\section{Experimental Section}

\subsection{Materials}

Fetal bovine serum (FBS), bovine serum albumin (BSA), trypsogen, and DMEM medium were purchased from Gibco (Grand Island, NY, USA). Sodium-acetate, sodium-propionate, sodium-butyrate, pertussis toxin (PTX), hyaluronidase, Dnase, and I type collagenase were provided by the Sigma Aldrich (St. Louis, MO, USA). Cell culture plates were purchased from Corning Incorporated (Corning, New York, USA). Bovine cAMP assay kit was purchased from R \& D Systems (Minneapolis, MN, USA). Anti-phospho CREB ( $\operatorname{Ser}^{133}$ ), anti-CREB antibodies, and PKA assay kit were purchased from Millipore (Billerica, MA, USA).

\subsection{Isolation and Culture of DCAPCs}

Pituitary glands were extracted from the heads of Holstein cows by electric saw at a local slaughterhouse and transported to the laboratory in HBSS solution without calcium and magnesium (CMF-HBSS) to which was added $50 \mu \mathrm{g}$ streptomycin/mL, and $100 \mathrm{IU}$ penicillin/mL at $5{ }^{\circ} \mathrm{C}$ within $2 \mathrm{~h}$. The posterior pituitary was removed with precision medical scissors and tweezers to obtain integrated anterior pituitary glands. Anterior pituitary glands were located were diced into small pieces less than $1 \mathrm{~mm}^{3}$ and incubated in CMF-HBSS containing $0.3 \%$ I type collagenase, $0.1 \%$ hyaluronidase and $0.1 \%$ DNase at $37{ }^{\circ} \mathrm{C}$ for $2 \mathrm{~h}$. The dispersed cells were washed three times with HBSS, resuspended in DMEM medium supplemented with $10 \%$ fetal bovine serum at seeding density of $1 \times 10^{3}$ cells $/ \mathrm{mL}$. Then, the cells were seeded into a $75 \mathrm{~cm}^{2}$ culture flask and incubated at $37{ }^{\circ} \mathrm{C}$ in a humidified atmosphere containing $5 \% \mathrm{CO}_{2}$. 


\subsection{Real-Time RT-PCR}

For real-time PCR analysis, DCAPCs were grown in 6-well plates $\left(5 \times 10^{5}\right.$ cells $)$, serum starved for $24 \mathrm{~h}$, and then stimulated with $0,0.1,0.5,1.0,2.5$, and $5.0 \mathrm{mmol} / \mathrm{L}$ acetate, propionate, or butyrate for $24 \mathrm{~h}$. PTX is the ADP-ribosylating toxin produced by the whooping cough causing bacterium Bordetella pertussis. ADP-ribosylation of the $\alpha$ subunit of heterotrimeric $G_{\alpha i}$ proteins locks the $\alpha$ subunits into an inactive state, thus it is unable to inhibit adenylyl cyclase [49]. It is widely applied as a tool in biochemical and pharmacological studies for the investigation of signaling pathways involving heterotrimeric G proteins [33]. DCAPCs were also treated with or without prior PTX incubation $(100 \mathrm{ng} / \mathrm{L})$ for $2 \mathrm{~h}$, and then stimulated with $1.0 \mathrm{mmol} / \mathrm{L}$ acetate, propionate, or butyrate for $24 \mathrm{~h}$. Total RNA was isolated from cells with trizol reagent (Invitrogen, Carlsbad, CA, USA) according to the manufacturer's instructions. Total RNA was treated with DNase I (Takara, Kyoto, Japan) to remove genomic DNA contamination. Total RNA concentration and purity was determined using a spectrophotometer (Bio-Rad, Hercules, CA, USA). Only samples with an optical density ratio at 260/280 nm 1.8-2.2 were used in further analysis. Total RNA integrity was checked by electrophoresis on an agarose gel. Total RNA samples were reverse transcribed using a reverse transcription kit (Takara, Kyoto, Japan) according to the manufacturer's instructions. The primer sequences of GH, PRL, Pit-1, and GAPDH genes (Table 1) were designed as Laporta et al. described [50]. GH, PRL, and Pit-1 expression were evaluated by quantitation RT-PCR analysis using the Premix Ex Taq ${ }^{\text {TM }}$ (Takara, Kyoto, Japan). The relative expression level for $G H, P R L$, and Pit-1 was calculated relative to GAPDH (the normalizer) using the comparative cycle threshold method [51,52].

Table 1. The primer sequences of bovine GAPDH, GH, PRL, and Pit-1.

\begin{tabular}{clc}
\hline Gene & \multicolumn{1}{c}{ Sequences } & Length (bp) \\
\hline \multirow{2}{*}{ GAPDH } & $\begin{array}{l}\text { (F)5'-TGCCCAGAATATCATCCC-3' } \\
\text { (R)5'-AGGTCAGATCCACAACAG-3' }\end{array}$ & 134 \\
\multirow{2}{*}{ GH } & $\begin{array}{l}\text { (F)5'-AGATCCTCAAGCAGACCTA-3' } \\
\text { (R)5'-AGGTACGTCTCCGTCTTA-3' }\end{array}$ & 121 \\
\multirow{2}{*}{$P R L$} & $\begin{array}{l}\text { (F)5'-TATGAAAGGAGCCCCAGATG-3' } \\
\text { (R)5'-CACACAGGGTAGGGCTCAGT-3' }\end{array}$ & \multirow{2}{*}{137} \\
\multirow{2}{*}{ Pit-1 } & $\begin{array}{l}\text { (F)5'-TTCTGCAACTCTGCCTCTGA-3' } \\
\text { (R)5'-CCATAGGTCGATGACTGGT-3' }\end{array}$ & \multirow{2}{*}{148} \\
\hline
\end{tabular}

\subsection{Measurement of Intracellular cAMP Concentration}

DCAPCs were grown in 6-well plates $\left(5 \times 10^{5}\right.$ cells $)$, serum starved for $24 \mathrm{~h}$, and then stimulated with $1.0 \mathrm{mmol} / \mathrm{L}$ acetate, propionate, or butyrate for the assigned period $(0.5,1,2,3 \mathrm{~h})$. The cAMP-dependent pathway is a GPCR-triggered signaling cascade. Thus, the intracellular cAMP was extracted from the cells and the concentration was assayed by microplate reader (Bio-Rad, Hercules, CA, USA) using rat cAMP assay kit according to the manufacturer's instructions. DCAPCs were also treated with or without prior PTX incubation (100 ng/L) for $2 \mathrm{~h}$, and then stimulated with $1.0 \mathrm{mmol} / \mathrm{L}$ acetate, propionate, or butyrate for $3 \mathrm{~h}$. The assay is based on the competition between unlabeled cAMP and a fixed quantity of horseradish peroxidase (HRP)-labeled cAMP for a limited number of binding sites of a cAMP specific antibody. 


\subsection{Measurement of PKA Activity}

cAMP works by activating protein kinase A (PKA), then, leads to the phosphorylation of cAMP response element binding protein (CREB). Thus, the PKA activity and phosphorylation levels of CREB were determined in this study. DCAPCs were cultured in the presence or absence of acetate, propionate, or butyrate $(1.0 \mathrm{mmol} / \mathrm{L})$ in FBS-F12 for $3 \mathrm{~h}$. The cells were also treated with prior PTX incubation (100 ng/L) for $2 \mathrm{~h}$ compared with groups without prior PTX incubation. Activity of PKA was determined using a radioactive method using PKA assay kit according to the manufacturer's instructions. Briefly, the lysates were incubated for $30 \mathrm{~min}$ at $30{ }^{\circ} \mathrm{C}$ with $100 \mu \mathrm{m}$ PKA-specific substrate, and $10 \mu \mathrm{Ci}$ of $\left[\gamma_{-}{ }^{32} \mathrm{P}\right] \mathrm{ATP}$ in kinase buffer, supplemented or not with PKA inhibitor peptide. The phosphorylated substrate was quantitated by using a liquid scintillation counter (Beckman coulter, Brea, CA, USA).

\subsection{Western Blotting Analysis of Phosphorylated CREB}

DCAPCs were grown in 6-well plates $\left(5 \times 10^{5}\right.$ cells $)$, serum starved for $24 \mathrm{~h}$, and then stimulated with $1.0 \mathrm{mmol} / \mathrm{L}$ acetate, propionate, or butyrate for $6 \mathrm{~h}$. Cells were also treated with prior PTX incubation $(100 \mathrm{ng} / \mathrm{L})$ for $2 \mathrm{~h}$ compared with groups without prior PTX incubation. Nuclear proteins were extracted by nuclear protein extraction kit according to the manufacturer's instructions (Beyotime Co., Nantong, China). Protein concentrations were determined by bicinchoninic acid (BCA) protein assay kit (Beyotime Co., Nantong, China). Aliquotes of cell lysates containing $20 \mu \mathrm{g}$ protein were separated in $10 \%$ polyacrylamide gels, electrophoretically transferred to PVDF membranes (Millipore, Billerica, MA, USA) using Bio-Rad criterion blotter (Bio-Rad, Hercules, CA, USA). Membranes were blocked in $5 \%$ non-fat, dried milk in TBST (50 mmol/L Tris, $\mathrm{pH} 7.5,0.15 \mathrm{~mol} / \mathrm{L} \mathrm{NaCl}, 0.05 \%$ Tween-20) at room temperature for $1 \mathrm{~h}$ and then incubated with either anti-phospho CREB (1:3000 dilution) or anti-CREB (1:2000 dilution) at $4{ }^{\circ} \mathrm{C}$ overnight. Blots were then washed and incubated with horseradish peroxidase-labeled secondary antibodies (Sigma Aldrich, St. Louis., MO, USA) at $37{ }^{\circ} \mathrm{C}$ for $1 \mathrm{~h}$. Immunoreactive bands were detected with enhanced chemiluminescence (ECL) western blotting detection reagents (Beyotime Co., Nantong, China). Blots were exposed to X-ray film for radiography of the bands. Blots were digitally detected and measured using a LAS3000 Bioimage Analyzer (Fuji Photo Film, Tokyo, Japan).

\subsection{Statistical Analyses}

Results were expressed as means \pm SD. Data were analyzed by using statistical software package SPSS 12.0 (SPSS Inc, Chicago, IL, USA). Groups were compared by one-way analysis of variance (ANOVA) followed by the least significant difference test. A $p$ value of less than 0.05 was considered statistically significant, and values less than 0.01 were considered markedly significant.

\section{Conclusions}

In summary, the results of this study indicate that SCFAs, as signaling molecules, significantly decrease GH and PRL gene transcription in DCAPCs, putatively according to the mechanism shown graphically in Figure 5. SCFAs bind to GPCR and lead to dissociation of heterotrimeric G protein 
complex into $G_{\alpha i}$ and $\beta \gamma$ subunit. The exchange of GTP from GDP results in activation of the $G_{\alpha i}$, thereby inhibiting adenylyl cyclase activity. Inactivated adenylyl cyclase results in a decrease of intracellular cAMP levels and a subsequent reduction in PKA activity. Inhibition of PKA activity inhibits CREB phosphorylation, thereby leading to a decrease of bovine $G H$ gene transcription. The change of the phosphorylation levels of CREB may decrease the phosphorylated CBP or CBP complex interacts with Pit-1 resultant inhibition of transcription of the bovine PRL gene. Consequently, SCFAs inhibit bovine $G H$ and $P R L$ gene transcription in DCAPCs. A-protomer of PTX penetrates into the host cells result in inactivation of $\mathrm{G}_{\alpha \mathrm{i}}$, hence, inhibits SCFAs mediated signaling pathway. In addition, inhibition of PKA activity may result in the decreased of $\mathrm{Ca}^{2+}$ influx through decreased L-type $\mathrm{Ca}^{2+}$ channel mean open time [53]. Therefore, SCFAs may also inhibit bovine GH and PRL secretion via $\mathrm{G}_{\mathrm{\alpha i}}$-mediated inhibition of $\mathrm{Ca}^{2+}$ channel. This study identifies a biochemical mechanism for the regulation of SCFAs on $G H$ and PRL gene transcription in DCAPCs, which may serve as one of the factors that regulate bovine pituitary function in accordance with dietary intake. Future studies will further research the role and mechanism of SCFAs in regulating bovine pituitary hormone secretion.

Figure 5. SCFAs inhibit the cAMP/PKA/CREB signaling pathway to mediate $G H$ and $P R L$ gene transcription in DCAPCs. SCFAs bind to GPCR and lead to dissociation of heterotrimeric $G$ protein complex into $G_{\alpha i}$ and $G_{\beta \gamma}$ subunit. The exchange of GTP from GDP results in activation of the $G_{\alpha i}$, thereby inhibiting adenylyl cyclase (AC) activity. This process results in a decrease of intracellular cAMP levels and a subsequent reduction in PKA activity. Inhibition of PKA activity inhibits CREB phosphorylation, thereby decreasing $G H$ and $P R L$ gene transcription directly or indirectly. The A-protomer of PTX penetrates into the host cells result in inactivation of $\mathrm{G}_{\alpha \mathrm{i}}$, hence, inhibits SCFAs mediated signaling pathway. In addition, inhibition of PKA activity may result in a decreased of $\mathrm{Ca}^{2+}$ influx through decreased L-type $\mathrm{Ca}^{2+}$ channel mean open time. Therefore, SCFAs may also inhibit bovine $\mathrm{GH}$ and PRL secretion via $\mathrm{G}_{\alpha \mathrm{i}}$-mediated inhibition of $\mathrm{Ca}^{2+}$ channel.

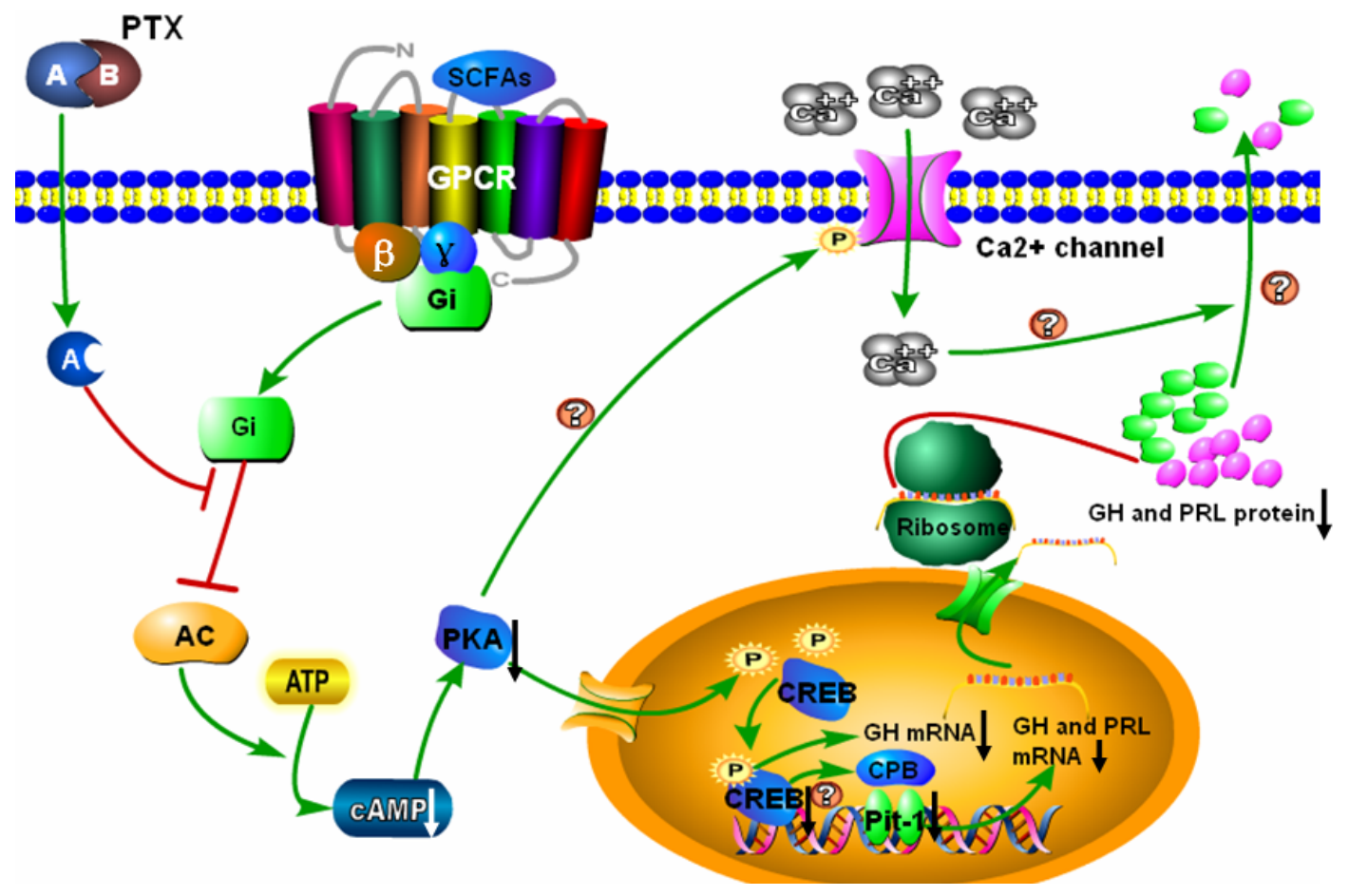




\section{Acknowledgments}

This work was founded by National Key Basic Research Program of China (Project No. 2011CB100805), Program for Changjiang Scholars and Innovative Research Team in University (PCSIRT, No. IRT1248) and Jilin Scientific and Technological Development Program (Project No. $20130206036 \mathrm{NY})$.

\section{Conflicts of Interest}

The authors declare no conflict of interest.

\section{References}

1. Ooi, G.T.; Tawadros, N.; Escalona, R.M. Pituitary cell lines and their endocrine applications. Mol. Cell Biol. 2004, 228, 1-21.

2. Akers, R.M. Major advances associated with hormone and growth factor regulation of mammary growth and lactation in dairy cows. J. Dairy Sci. 2006, 89, 1222-1234.

3. Capuco, A.V.; Wood, D.L.; Baldwin, R.; McLeod, K.; Paape, M.J. Mammary cell number, proliferation, and apoptosis during a bovine lactation: Relation to milk production and effect of bst. J. Dairy Sci. 2001, 84, 2177-2187.

4. Yang, J.; Zhao, B.; Baracos, V.E.; Kennelly, J.J. Effects of bovine somatotropin on $\beta$-casein mrna levels in mammary tissue of lactating cows. J. Dairy Sci. 2005, 88, 2806-2812.

5. Yonekura, S.; Sakamoto, K.; Komatsu, T.; Hagino, A.; Katoh, K.; Obara, Y. Growth hormone and lactogenic hormones can reduce the leptin mRNA expression in bovine mammary epithelial cells. Domest. Anim. Endocrinol. 2006, 31, 88-96.

6. Freeman, M.E.; Kanyicska, B.; Lerant, A.; Nagy, G. Prolactin: Structure, function, and regulation of secretion. Physiol. Rev. 2000, 4, 1523-1631.

7. Trott, J.F.; Schennink, A.; Petrie, W.K.; Manjarin, R.; VanKlompenberg, M.K.; Hovey, R.C. Triennial lactation symposium: Prolactin: The multifaceted potentiator of mammary growth and function. J. Anim. Sci. 2012, 95, 1674-1686.

8. Wong, J.M.; Souza, R.; Kendall, C.W.; Dumas, M.E. Colonic health: Fermentation and short chain fatty acids. J. Clin. Gastroenterol. 2006, 40, 235-243.

9. Sutton, J.D.; Dhanoa, M.S.; Morant, S.V.; France, J.; Napper, D.J.; Schuller, E. Rates of production of acetate, propionate, and butyrate in the rumen of lactating dairy cows given normal and low-roughage diets. J. Dairy Sci. 2003, 86, 3620-3633.

10. Vinolo, M.A.; Rodrigues, H.G.; Nachbar, R.T.; Curi, R. Regulation of inflammation by short chain fatty acids. Nutrients 2011, 3, 858-876.

11. Slavin, J. Fiber and prebiotics: Mechanisms and health benefits. Nutrients 2013, 5, 1417-1435.

12. Blottiere, H.M.; Buecher, B.; Galmiche, J.P.; Cherbut, C. Molecular analysis of the effect of short-chain fatty acids on intestinal cell proliferation. Proc. Nutr. Soc. 2003, 62, 101-106.

13. Mineo, H.; Hashizume, Y.; Hanaki, Y.; Murata, K.; Maeda, H.; Onaga, T.; Kato, S.; Yanaihara, N. Chemical specificity of short-chain fatty acids in stimulating insulin and glucagon secretion in sheep. Am. J. Physiol. 1994, 267, E234-E241. 
14. Kato, S.; Sato, K.; Chida, H.; Roh, S.G.; Ohwada, S.; Sato, S.; Guilloteau, P.; Katoh, K. Effects of Na-butyrate supplementation in milk formula on plasma concentrations of GH and insulin, and on rumen papilla development in calves. J. Endocrinol. 2011, 211, 241-248.

15. Yen, P.M.; Tashjian, A.H., Jr. Short chain fatty acids increase prolactin and growth hormone production and alter cell morphology in the GH3 strain of rat pituitary cells. Endocrinology 1981, $109,17-22$.

16. Ishiwata, H.; Nagano, M.; Sasaki, Y.; Chen, C.; Katoh, K. Short-chain fatty acids inhibit the release and content of growth hormone in anterior pituitary cells of the goat. Gen. Comp. Endocrinol. 2000, 118, 400-406.

17. Brown, A.J.; Goldsworthy, S.M.; Barnes, A.A.; Eilert, M.M.; Tcheang, L.; Daniels, D.; Muir, A.I.; Wigglesworth, M.J.; Kinghorn, I.; Fraser, N.J.; et al. The Orphan G protein-coupled receptors GPR41 and GPR43 are activated by propionate and other short chain carboxylic acids. J. Biol. Chem. 2003, 278, 11312-11319.

18. Tazoe, H.; Otomo, Y.; Kaji, I.; Tanaka, R.; Karaki, S.I.; Kuwahara, A. Roles of short-chain fatty acids receptors, GPR41 and GPR43 on colonic functions. J. Physiol. Pharmacol. 2008, 59, 251-262.

19. Wang, A.; Gu, Z.; Heid, B.; Akers, R.M.; Jiang, H. Identification and characterization of the bovine G protein-coupled receptor GPR41 and GPR43 genes. J. Dairy Sci. 2009, 92, 2696-2705.

20. Nelson, C.; Albert, V.R.; Elsholtz, H.P.; Lu, L.I.; Rosenfeld, M.G. Activation of cell-specific expression of rat growth hormone and prolactin genes by a common transcription factor. Science 1988, 239, 1400-1405.

21. Sanchez-Pacheco, A.; Palomino, T.; Aranda, A. Negative regulation of expression of the pituitary-specific transcription factor GHF-1/Pit-1 by thyroid hormones through interference with promoter enhancer elements. Mol. Cell Biol. 1995, 15, 6322-6330.

22. Schaufele, F.; West, B.L.; Reudelhuber, T.L. Overlapping Pit-1 and Sp1 binding sites are both essential to full rat growth hormone gene promoter activity despite mutually exclusive Pit-1 and Sp1 binding. J. Biol. Chem. 1990, 265, 17189-17196.

23. Gaiddon, C.; Tian, J.; Loeffler, J.P.; Bancroft, C. Constitutively active $\mathrm{G}(S) \alpha$-subunits stimulate Pit-1 promoter activity via a protein kinase A-mediated pathway acting through deoxyribonucleic acid binding sites both for Pit-1 and for adenosine 3',5'-monophosphate response element-binding protein. Endocrinology 1996, 137, 1286-1291.

24. Topping, D.L.; Clifton, P.M. Short-chain fatty acids and human colonic function: Roles of resistant starch and nonstarch polysaccharides. Physiol. Rev. 2001, 81, 1031-1064.

25. Den Hond, E.; Hiele, M.; Evenepoel, P.; Peeters, M.; Ghoos, Y.; Rutgeerts, P. In vivo butyrate metabolism and colonic permeability in extensive ulcerative colitis. Gastroenterology 1998, 115, 584-590.

26. Annison, G.; Illman, R.J.; Topping, D.L. Acetylated, propionylated or butyrylated starches raise large bowel short-chain fatty acids preferentially when fed to rats. J. Nutr. 2003, 133, 3523-3528.

27. Sauer, J.; Richter, K.K.; Pool-Zobel, B.L. Products formed during fermentation of the prebiotic inulin with humangut flora enhance expression of biotranformation genes in human primary colon cells. Br. J. Nutr. 2007, 97, 928-937.

28. Hamer, H.M.; Jonkers, D.; Venema, K.; Vanhoutvin, S.; Troost, F.J.; Brummer, R.J. Review article: The role of butyrate on colonic function. Aliment. Pharmacol. Ther. 2008, 27, 104-119. 
29. Gibson, G.R.; Roberfroid, M.B. Dietary modulation of the human colonic micro- biota: Introducing the concept of prebiotics. J. Nutr. 1995, 125, 1401-1412.

30. Pan, X.D.; Chen, F.Q.; Wu, T.X.; Tang, H.G.; Zhao, Z.Y. Prebiotic oligosaccharides change the concentrations of short-chain fatty acids and the microbial population of mouse bowel. J. Zhejiang Univ. Sci. B 2009, 10, 258-263.

31. Thomsen, W.; Frazer, J.; Unett, D. Functional assays for screening GPCR targets. Curr. Opin. Biotechnol. 2005, 16, 655-665.

32. El-Armouche, A.; Zolk, O.; Rau, T.; Eschenhagen, T. Inhibitory G-proteins and their role in desensitization of the adenylyl cyclase pathway in heart failure. Cardiovasc. Res. 2003, 60, 478-487.

33. Mangmool, S.; Kurose, $\mathrm{H}_{\text {. }} \mathrm{G}_{\mathrm{i} / \mathrm{o}}$ protein-dependent and -independent actions of pertussis toxin (PTX). Toxins 2011, 3, 884-899.

34. Tian, C.; Ye, F.; Xu, T.; Wang, S.; Wang, X.; Wang, H.; Wan, F.; Lei, T. GHRP-6 induces CREB phosphorylation and growth hormone secretion via a protein kinase $\mathrm{C} \sigma$-dependent pathway in $\mathrm{GH}_{3}$ cells. J. Huazhong Univ. Sci. Technol. 2010, 30, 183-187.

35. Jean, A.; Gutierrez-Hartmann, A.; Duval, D.L. A Pit-1 threonine 220 phosphomimic reduces binding to monomeric DNA sites to inhibit Ras and estrogen stimulation of the prolactin gene promoter. Mol. Endocrinol. 2010, 24, 91-103.

36. Kapiloff, M.S.; Farkash, Y.; Wegner, M.; Rosenfeld, M.G. Variable effects of phosphorylation of Pit-1 dictated by the DNA response elements. Science 1991, 253, 786-789.

37. Caelles, C.; Hennemann, H.; Karin, M. M-phase-specific phosphorylation of the POU transcription factor GHF-1 by a cell cycle-regulated protein kinase inhibits DNA binding. Mol. Cell Biol. 1995, 15, 6694-6701.

38. Cohen, L.E.; Hashimoto, Y.; Zanger, K.; Wondisford, F.; Radovick, S. CREB-independent regulation by $\mathrm{CBP}$ is a novel mechanism of human growth hormone gene expression. J. Clin. Invest. 1999, 104, 1123-1130.

39. Lundblad, J.R.; Kwok, R.P.S; Laurance, M.E.; Harter, M.L.; Goodman, R.H. Adenoviral E1A-associated p300 as a functional homologue of the transcriptional co-activator CBP. Nature 1995, 374, 85-88.

40. Lane, M.A.; Jesse, B.W. Effect of volatile fatty acid infusion on development of the rumen epithelium in neonatal sheep. J. Dairy Sci. 1997, 80, 740-746.

41. Zhao, G.Y.; Sun, Y.B. Effects of volatile fatty acids on IGF-I, IGFBP-3, GH, insulin and glucagon in plasma, and IGF-I and IGFBP-3 in different tissues of growing sheep nourished by total intragastric infusions. Asian-Aust. J. Anim. Sci. 2010, 23, 366-371.

42. Matsunaga, N.; Kubota, I.; Roh, S.G.; He, M.L.; Hidaka, S.; Hidari, H.; Sasaki, Y. Effect of mesenteric venous volatile fatty acids (VFA) infusion on GH secretion in sheep. Endocr. J. 1997, 44, 707-714.

43. Matsunaga, N.; Arakawa, N.T.; Goka, T.; Nam, K.T.; Ohneda, A.; Sasaki, Y.; Katoh, K. Effects of ruminal infusion of volatile fatty acids on plasma concentration of growth hormone and insulin in sheep. Domest. Anim. Endocrinol. 1999, 17, 17-27. 
44. Matsunaga, N.; Goka, T.; Nam, K.T.; Oda, S.; Ohneda, A.; Sasaki, Y. Inhibition of GH releasing factor (GRF)-induced GH secretion by intraruminal infusion of volatile fatty acids (VFA) in sheep. Endocr. J. 1997, 44, 133-140.

45. Katoh, K.; Takahashi, T.; Kobayashi, Y.; Obara, Y. Somatotropic axis and nutrition in young ruminants around weaning time. Asian-Aust. J. Anim. Sci. 2007, 20, 1156-1168.

46. Wang, J.F.; Fu, S.P.; Li, S.N.; Yang, Z.Q.; Xue, W.J.; Li, Z.Q.; Wang, W.; Liu, J.X. Establishment and characterization of dairy cow growth hormone secreting anterior pituitary cell model. In Vitro Cell Dev. Biol. Anim. 2013, in press.

47. Sato, H.; Kurosawa, T.; Oikawa, S. Acetic acid and 3-hydroxybutyric acid levels in cerebrospinal fluid of cattle. Anim. Sci. J. 2002, 73, 137-141.

48. Laeger, T.; Sauerwein, H.; Tuchscherer, A.; Bellmann, O.; Metges, C.C.; Kuhla, B. Concentrations of hormones and metabolites in cerebrospinal fluid and plasma of dairy cows during the periparturient period. J. Dairy Sci. 2013, 96, 2883-2893.

49. Bruckener, K.E.; el Baya, A.; Galla, H.J.; Schmidt, M.A. Permeabilization in a cerebral endothelial barrier model by pertussis toxin involves the PKC effector pathway and is abolished by elevated levels of cAMP. J. Cell Sci. 2003, 116, 1837-1846.

50. Laporta, J.; Driver, A.; Khatib, H. Short communication: Expression and alternative splicing of POU1F1 pathway genes in preimplantation bovine embryos. J. Dairy Sci. 2011, 94, 4220-4223.

51. Livak, K.J.; Schmittgen, T.D. Analysis of relative gene expression data using real-time quantitative PCR and the $2^{-\Delta \Delta C(\mathrm{~T})}$ method. Methods 2001, 25, 402-408.

52. Lisowski, P.; Pierzcha, M.; Gooecik, J. Evaluation of reference genes for studies of gene expression in the bovine liver, kidney, pituitary, and thyroid. J. Appl. Genet. 2008, 49, 367-372.

53. Wehrens, X.H.; Lehnart, S.E.; Reiken, S.; Vest, J.A.; Wronska, A.; Marks, A.R. Ryanodine receptor/calcium release channel PKA phosphorylation: A critical mediator of heart failure progression. Proc. Natl. Acad. Sci. USA 2006, 103, 511-518.

(C) 2013 by the authors; licensee MDPI, Basel, Switzerland. This article is an open access article distributed under the terms and conditions of the Creative Commons Attribution license (http://creativecommons.org/licenses/by/3.0/). 